\title{
Pluralidade de estratégias e adoção de um paradigma: Hugh Lacey, Thomas Kuhn e as abordagens da pesquisa científica
}

\author{
Plurality strategies and adoption of a paradigm: Hugh Lacey, \\ Thomas kuhn and approaches of scientific research
}

Camila Lantiman

Mestre em Filosofia pela Uerj

camilalantiman@gmail.com

Recebido em 09/10/16

Aceito em 22/11/16

Para citar este artigo: LANTIMAN, Camila. Pluralidade de estratégias e adoção de um paradigma: Hugh Lacey, Thomas Kuhn e as abordagens da pesquisa científica. Em Construção. ano 1, n. 1, 2017, pp. 69-80. DOI:10.12957/emconstrucao.2017.28125

\section{Resumo}

É cada vez maior o reconhecimento da ciência como uma produção da atividade humana, cujo desenvolvimento pode envolver perspectivas valorativas. Embora tenha como objetivo a produção de conhecimento comprovado do mundo, a ciência só poderia alcançar plenamente seu fim se o resultado produzido por ela visar também ao bem-estar de todos. Neste aspecto, que tipo de abordagens poderiam ser utilizadas para atingir tal finalidade? Talvez a adoção de um único procedimento metodológico não seja suficiente para abranger todas as possibilidades existentes, restringindo consideravelmente a atividade científica. Tomando como base as contribuições feitas por Thomas Kuhn e Hugh Lacey é possível observar dois pontos importantes: enquanto Kuhn apresenta uma ciência normal baseada na escolha de um único paradigma, Lacey admite a ação de múltiplas estratégias que poderão atuar simultaneamente. Diante dos grandes avanços tecnológicos e das demandas impostas à ciência, tendemos a acreditar que a utilização de uma pluralidade de estratégias poderá ser considerada o meio mais viável para atingir a meta proposta.

Palavras-Chave: Atividade Científica; valores; bem-estar; estratégias; paradigmas.

\section{Abstract}

There is increasing recognition of science as a production of human activity, whose development may involve valuing perspectives. Although it aims at producing the world's proven knowledge, science could only fully attain its end if the result produced by it also aimed at the well-being of all. In this respect, what kind of approaches could be used to achieve this? Perhaps the adoption of a single methodological procedure is not sufficient to cover all possibilities, restricting considerably the scientific activity. Taking the contributions made by Thomas Kuhn and Hugh Lacey is possible to observe two important points: while Kuhn presents a normal science based on the choice of a single paradigm, Lacey admits the action of multiple strategies that can act simultaneously. Faced with the great technological advances and the demands imposed on science, we tend to believe that the use of a plurality of strategies can be considered the most viable means to reach the proposed goal.

Key Words: Scientific activity; values; welfare; strategies; paradigms. 


\section{Introdução}

Em constante avanço, a tecnociência ${ }^{1}$ e suas progressivas inovações evoluem, demonstrando seu alto poder de modificação da vida humana e do meio ambiente. Ela oferece novas facilidades, novos processos produtivos - cada vez mais autônomos e imediatos - e apresenta produtos modificados e aperfeiçoados, baseados em tecnologias desenvolvidas por indivíduos engajados em pesquisas científicas com o fim de alcançar resultados satisfatórios e comprováveis.

O progresso apresentado pela ciência e pela tecnologia, além de produzir grandes benefícios, também originou questões preocupantes. Mesmo diante da intensa evolução e dos grandes avanços proporcionados em diversas áreas, o mau uso do conhecimento e das ferramentas disponibilizadas configura uma grande fonte de problemas e controvérsias, principalmente quando constata-se que muitas das inovações são desenvolvidas por grandes empresas e impérios industrias com valores consideráveis de investimentos em pesquisa.

Como exemplo, temos a pesquisa sobre alimentos geneticamente modificados - mais conhecidos como alimentos transgênicos -, que gerou (e ainda gera) vigorosos debates que caracterizam duas posições distintas: aqueles que defendem a implantação e utilização dos transgênicos em larga escala e aqueles que endossam argumento contra a utilização deste tipo de cultura.

A discussão sobre os transgênicos e os argumentos prós e contra possuem âmbito mundial e são potencializados principalmente por dois grupos: os representantes da biotecnologia e do agronegócio - que defendem a disseminação dos transgênicos pelo mundo e afirmam que as sementes transgênicas constituem uma forma eficaz de combate à fome - e os representantes da agroecologia - que defendem a produção sustentável de alimentos, sua distribuição igualitária e alternativas que produzam menos riscos e maiores benefícios, como a agroecologia (LACEY, 2006, p. 149).

Considerada a melhor alternativa apresentada pela biotecnologia para o problema da escassez de alimentos e consequentemente o combate a fome no mundo, a tecnologia transgênica aplicada aos alimentos constitui um progresso tecnológico importante, mas é explorada e desenvolvida por impérios industriais que claramente possuem outros tipos de interesses não relacionados à erradicação da fome.

A produção de alimentos geneticamente modificados depende de investimentos de alto custo em terras, compra de sementes, material, maquinário e mão de obra. Pequenos agricultores, agriculturas familiares e de subsistência teriam poucas condições de competir de forma igualitária com os grandes produtores de alimentos, uma vez que as sementes transgênicas não podem ser reproduzidas a partir do que se plantou.

Diante dos benefícios e problemas apresentados pelas pesquisas acerca de alguns objetos de estudos, é possível refletir sobre os seguintes questionamentos: que tipos de abordagens podem ser utilizados, na pesquisa científica, para que o maior número de possibilidades seja considerado? O que deve ser levado em consideração durante a pesquisa para que esta gere resultados com equanimidade? Que abordagens devem ser ponderadas a fim de conseguir resultados comprovados que garantam o bem-estar de todos? $\mathrm{E}$ ainda: admitindo-se como objetivo da ciência a obtenção de conhecimento comprovado do mundo e dos fenômenos e uma vez considerada como produto humano, quais caminhos deve a ciência seguir para que seu objetivo seja plenamente alcançado?

Essas questões são importantes e geram debates infindáveis. Contudo, através de duas concepções importantes sobre o desenvolvimento científico, poderemos fornecer, na medida do possível, uma discussão acerca das abordagens que podem ser utilizadas nas práticas científicas com o fim de atingir o objetivo da ciência, bem como a possibilidade de que seus resultados beneficiem o maior grupo de indivíduos possível.

1 A tecnociência, grosso modo, aborda as implicações da tecnologia e da ciência, bem como seus riscos e impactos. A interação entre ciência e tecnologia ao longo do tempo se intensificou e o termo tecnociência foi incorporado na contemporaneidade. A sociedade tecnocientífica que temos hoje é o resultado das diversas revoluções científicas e tecnológicas ocorridas nos últimos anos. 
Utilizaremos dois autores importantes que irão direcionar o presente estudo: Thomas Kuhn, que apresenta uma abordagem científica baseada na emergência de um paradigma fruto de uma revolução científica e Hugh Lacey, que possui uma compreensão do desenvolvimento científico baseado na atuação de múltiplas estratégias no interior de uma determinada pesquisa.

Segundo Lacey, a estratégia constitui uma modificação da noção de paradigma de Kuhn. Enquanto o paradigma restringe os fatos que serão considerados por uma determinada comunidade científica para que esta possa conhecê-los mais profundamente, a estratégia possui o papel de restringir o tipo de teoria considerada e selecionar os dados empíricos a serem considerados para o fim de testar as várias teorias provisoriamente mantidas (LACEY, 2009).

Considerada a ligação entre os dois elementos é possível afirmar que enquanto Kuhn apresenta uma ciência normal baseada em um paradigma vigente, Lacey admite a ação de múltiplas estratégias que poderão atuar simultaneamente, sendo a questão fundamental a escolha e compatibilidade entre elas (LACEY, 2001).

Neste estudo, não desenvolveremos as ideias de cada autor minuciosamente. Por caracterizar duas ideais que abrangem muitas considerações e conceitos importantes, o enfoque estará direcionado às abordagens utilizadas de forma geral com o fim de discutir o tema proposto.

\section{0 modelo paradigmático de desenvolvimento científico}

Responsável por importantes contribuições à filosofia e à história da ciência, o físico norte-americano Thomas Kuhn pode ser considerado como uma das importantes influências à compreensão das práticas científicas modernas ao atribuir um caráter paradigmático à ciência (HACKING, 2012, p.136). A Estrutura das Revoluções Científicas (ERC) foi o principal trabalho de Kuhn e, também, o mais conhecido e criticado. A obra sintetiza as ideais e os anseios de Kuhn em relação à ciência e, através dela, ele se tornou conhecido como um teórico com conceitos voltados mais para a História e Filosofia da Ciência, do que para a Física, que era sua formação.

Os estudos kuhnianos se opõem significativamente à concepção científica tradicional apresentada pelo positivismo lógico no início do século XX que, em poucas palavras, propunha principalmente uma ciência unificada, anti-metafísica, baseada em um único método científico e com linguagem única. Pensar em uma ciência restrita, baseada em uma única metodologia limitava demasiadamente as possibilidades que poderiam ser alcançadas por ela. Um novo quadro científico era formado não somente com Kuhn, mas com consideráveis contribuições de outros teóricos como, por exemplo, Van Quine, Karl Popper e Hilary Putnam. A ciência ganhava um novo formato e a imagem de um cientista solitário envolvido com sua pesquisa começa a se desfazer, dando lugar a uma ciência considerada como um empreendimento determinado pelos esforços de um grupo de indivíduos empenhados em uma pesquisa: a comunidade científica.

A História se configurava ferramenta fundamental para a compreensão da ciência e, neste contexto, Kuhn propôs uma nova compreensão em relação a atividade científica: uma atividade situada e determinada historicamente, conduzida por agentes humanos também situados e determinados historicamente - logo, uma atividade humana. Esse modelo de argumentação apresentado por Kuhn a respeito da ciência e de seu desenvolvimento proporcionou, também, uma importante aproximação entre os campos da História da Ciência e da Filosofia da Ciência. A adequada interlocução entre os dois campos apresentados, se bem-sucedida, proporcionará um importantes considerações e entendimento do progresso científico (KUHN, 1977, p. 25).

De acordo com Kuhn, existe uma necessidade de diálogo entre esses dois campos, mas esta interação deve ser interdisciplinar e não intradisciplinar, ou seja, a relação entre as duas deve ser realizada externamente e não internamente. A possibilidade de interação entre as duas áreas não deve ser relacionada a uma fusão de seus interesses, que claramente são divergentes. O resultado provável disso será a confusão da base disciplinar de cada uma delas. Ambas as áreas são importantes uma para a outra e as duas são importantes para entender o que é a ciência. Desta forma, é importante ressaltar que é possível realizar este entendimento sem que haja a necessidade de se realizar uma fusão entre os dois campos. Essa interação deve ser estabelecida buscando, 
primeiramente, um diálogo entre as duas disciplinas e mantendo a possibilidade de cada uma existir com a sua integridade estrutural.

Kuhn introduziu o termo paradigma, definido por ele como um conjunto de realizações científicas que determinada comunidade compartilha e que durante algum tempo proporciona soluções modelares para os problemas apresentados pela pesquisa (KUHN, 1992, p.13). Em outras palavras, o paradigma forma a base da pesquisa científica, pois representa todo um conjunto de crenças, valores e técnicas partilhados por membros de uma mesma comunidade científica.

Detentor de um caráter exemplar no interior das práticas científicas, o paradigma propõe uma nova compreensão às práticas científicas ao passo que também apresentou dificuldades acerca de sua interpretação. O modelo de desenvolvimento científico paradigmático gerou muitas discussões e, na tentativa de se fazer melhor compreendido, na segunda edição da $E R C$, Kuhn apresentou um pós-escrito, com considerações acerca de algumas de suas ideias que foram alvo de problematizações. Uma delas, especialmente, voltada para a melhor explicação do conceito de incomensurabilidade.

Neste artigo a questão da incomensurabilidade não será abordada com profundidade, pois se trata de um problema que possui diversas interpretações. Aqui, consideraremos a incomensurabilidade como um princípio pelo qual é afirmado que paradigmas diferentes estabelecem visões de mundo também distintas e desse modo não podem ser comparados (KUHN, 2006; HACKING, 2012).

No modelo de desenvolvimento científico, o período de ciência normal é caracterizado pela vigência de um paradigma que possui a função de orientar a investigação científica e oferecer os subsídios necessários para que os cientistas sejam capazes de solucionar os problemas que surgem no decorrer da pesquisa.

Kuhn define a ciência normal como "a pesquisa firmemente baseada em uma ou mais realizações científicas passadas" (KUHN, 1992, p.29). Neste momento da atividade científica pode ocorrer uma restrição significativa da visão do cientista em relação as possibilidades apresentadas pelo paradigma vigente, mas essa restrição decorre da confiança que eles depositam nele. Assim, o paradigma possuirá a função de direcionar a pesquisa científica durante todo o período de ciência normal.

A adaptação a um novo paradigma constitui um processo que demanda tempo. Essa espécie de jogo da ciência, caracterizado por Kuhn como um quebra-cabeça científico (puzzles ${ }^{2}$ ), gera motivação aos cientistas e surge para testar as habilidades dos praticantes da ciência na resolução dos novos problemas que se apresentam. Portanto:

Resolver um problema da pesquisa normal é alcançar o antecipado de uma nova maneira. Isso requer a solução de todo o tipo de complexos quebra-cabeças instrumentais, conceituais e matemáticos. $\mathrm{O}$ indivíduo que é bem sucedido nessa tarefa prova que é um perito na resolução de quebra-cabeças. O desafio apresentado pelo quebra-cabeça constitui uma parte importante da motivação do cientista para o trabalho (KUHN, 1992, p. 59).

Novos compromissos são colocados à comunidade cientifica e aos seus integrantes. As abordagens e critérios de pesquisa para resolução de determinado problema também são alterados (KUHN, 1992, p 145). Durante o período de ciência normal, caracterizado pela instalação e vigência de um novo paradigma, este será satisfatório para solucionar todas as questões apresentadas pelos cientistas.

Entretanto, o paradigma possui "vida útil", um prazo determinado de atuação que será definido por sua fecundidade. As mudanças de paradigmas ocorrem quando a fecundidade se esgota, isto é, o paradigma não consegue mais responder satisfatoriamente aos questionamentos apresentados tanto pelos cientistas como pelos novos fenômenos que aparecem (LACEY, 2010, p. 71).

2 Termo usado por Kuhn para caracterizar os quebra-cabeças instrumentais, conceituais e matemáticos aos quais os cientistas se deparam durante a pesquisa. 
Este momento é complexo e causa alteração de ideias, de práticas e de teorias científicas que, consequentemente, serão substituídas por outras mais eficientes e adequadas para resolução dos problemas apresentados. Quando a fecundidade de um paradigma se esgota (considerada por Kuhn como a apresentação de anomalia) sobrevém um período de crise no interior da comunidade científica até que um novo paradigma emerja, caracterizando a revolução científica. Em outras palavras, quando determinados paradigmas apresentam anomalias, deixam lacunas que serão gradualmente completadas por paradigmas que as sucederam.

As revoluções científicas proporcionam novos compromissos e bases às práticas científicas. Kuhn as define como "complementos desintegradores da tradição à qual a atividade da ciência normal está ligada" (KUHN, 1992, p.25). O surgimento de um novo paradigma transforma consideravelmente os caminhos que anteriormente direcionavam o trabalho dos indivíduos de uma comunidade científica. A nova teoria tem o poder de causar impactos tanto em projetos não finalizados como sobre aqueles concluídos com base na teoria antiga.

Diante de uma "nova visão de mundo", proporcionada pelo novo paradigma, o cientista resolverá os novos questionamentos da pesquisa à luz dele, até que apareçam novos problemas que o desafiem. Com a emergência de um novo paradigma a maneira como os cientistas encaram o mundo é modificada. Essa mudança na visão de mundo, ocasionada pelo paradigma, pode ser exemplificada na transição da teoria de Ptolomeu para Copérnico e na transição da Física aristotélica para newtoniana.

Assim, os cientistas podem se dedicar aos fenômenos selecionados, permitindo que a pesquisa se torne cada vez mais orientada. A ciência normal também é caracterizada como um período onde a pesquisa se torna mais especializada, ou seja, o paradigma apresenta os fenômenos que serão relevantes e esses serão articulados dentro da pesquisa tornando-a cada vez mais particularizada. De acordo com Kuhn:

(...) a pesquisa científica normal está dirigida para a articulação daqueles fenômenos e teorias já fornecidos pelo paradigma. Talvez essas características sejam defeitos. As áreas investigadas pela ciência normal são certamente minúsculas; ela restringe drasticamente a visão do cientista. Mas essas restrições nascidas da confiança no paradigma, revelaramse essenciais para o desenvolvimento da ciência. Ao concentrar a atenção numa faixa de problemas relativamente esotéricos, o paradigma força os cientistas a investigar alguma parcela da natureza com uma profundidade e de uma maneira não detalhada que, de outro modo seriam inimagináveis (KUHN, 1992, p.45).

A articulação do paradigma no período de ciência normal gera um aprofundamento do fenômeno observado caminhando, assim, em direção a especialização. O domínio dos fatos explicáveis pela ciência aumentou significativamente e o conhecimento em diversos campos da ciência são aprofundados. Este fato gera uma restrição drástica dos fenômenos e das diversas possibilidades que eles podem apresentar.

A especialização fornece condições para que a ciência progrida, produz resultados muito relevantes e é necessária para a constituição de um entendimento aprofundado sobre determinados fenômenos, mas também está associada a fatores indesejáveis que podem acometer a pesquisa como, por exemplo, a produção de um conhecimento fragmentado ou enclausurado (MENDONÇA; VIDEIRA, 2007) ${ }^{3}$.

\section{A importância das estratégias à pesquisa cientifica}

Apresentando um modelo de ciência focado em questões atuais que giram em torno da produção, desenvolvimento e aplicação do conhecimento científico, Hugh Lacey enfatiza em seus estudos a influência dos valores na atividade científica. Com o progresso científico e o desenvolvimento de novas tecnologias, atualmente a interação entre ciência e valores tem se tornado cada vez mais discutida e analisada por histo-

3 Ao longo do texto a questão da especialização será rapidamente retomada através do que Hugh Lacey chama de "estratégias materialistas ou de abordagem descontextualizada". 
riadores, sociólogos e críticos da ciência, principalmente em importantes encontros, como o Fórum Social Mundial ${ }^{4}$, por exemplo.

A ciência tem ganhado destaque como um empreendimento humano desenvolvido por indivíduos engajados e que possuem objetivos e anseios. Há uma expectativa tanto dos componentes de uma comunidade científica quanto da sociedade em relação à ciência. Mas como responder a esses anseios de modo adequado?

Em primeiro lugar, Lacey define o lugar e o papel que os valores ocupam em seu modelo de desenvolvimento científico. Os valores cognitivos possuem importância fundamental na escolha de teorias científicas e são constitutivos da ciência. Eles representam as propriedades das teorias que julgamos serem constituintes de uma boa teoria, por exemplo: adequação empírica, consistência, simplicidade, fecundidade, eficácia, poder explicativo, verdade e certeza. Os valores não cognitivos são aqueles que não possuem relação com a aceitabilidade de uma teoria científica como, por exemplo: valores éticos, sociais, políticos, religiosos, etc.

A tese de uma ciência livre de valores constitui uma das bases das discussões propostas por Lacey. Tendo sua base em Galileu Galilei, esta tese possui três elementos importantes: a imparcialidade, a neutralidade e autonomia (LANTIMAN, 2015, p. 18).

Em Valores e Atividade Científica, volumes 1 (LACEY, 2008) e 2 (LACEY, 2010), ele defende que a imparcialidade é a única que pode ser sustentada no interior das práticas científicas, uma vez que é baseada apenas em valores cognitivos. A imparcialidade sustenta que a teoria, para que seja corretamente aceita, deve manifestar critérios cognitivos em grau suficientemente elevado, a luz dos dados empíricos. Ela forma um escudo que impede que valores não cognitivos sejam inseridos ou desempenhem algum papel no momento de avaliação de teorias.

A autonomia está relacionada principalmente aos membros de determinada pesquisa, a pesquisa científica em si e suas metodologias e ao modo pelo qual são guiadas. É cada vez mais evidente que os anseios das grandes indústrias e corporações estão fundamentados em interesses econômicos (visando principalmente o lucro e o aumento do capital) e de mercado (onde há forte investimento na expansão de seus poderes e negócios). A determinação de prazos, muitas vezes reduzidos, impede o desenvolvimento das possibilidades que podem ser alcançadas pela ciência e suplantam os interesses de formação de conhecimento e entendimento de novos fenômenos.

A neutralidade, de modo geral, informa que os resultados produzidos pela pesquisa científica, avaliados e aceitos de acordo com a imparcialidade, não possuem implicação lógica para qualquer perspectiva valorativa, seja ela política, ética, social, etc. Ao mesmo tempo, promove que as teorias, quando corretamente aceitas, podem se adequar a qualquer perspectiva de valor, ideologia ou visão de mundo.

Lacey proporciona uma variação do modelo kuhniano de desenvolvimento científico, onde a pesquisa científica é guiada pelo que ele denomina estratégias de restrição e seleção. A adoção de uma estratégia, segundo Lacey, define os tipos de fenômenos e as possibilidades que serão consideradas interessantes à pesquisa. A estratégia possui o papel de restringir os tipos de teorias que serão consideradas em determinada pesquisa e selecionar os dados empíricos relevantes (LACEY, 2008, p.109).

Posto que não existe uma única metodologia científica, a questão metodológica inicial será a escolha de uma ou mais estratégias com o fim de direcionar a pesquisa para obtenção de determinado objetivo. Assim, a escolha da estratégia poderá variar de acordo com as características do objeto de investigação:

O Fórum Mundial Social é um encontro anual de âmbito internacional promovido por movimentos sociais, organizações não-governamentais e com a participação da comunidade civil com o intuito de promover discussão acerca das desigualdades provocadas pela globalização e a busca de alternativas para a transformação social. Hugh Lacey apresenta uma lista desses valores apresentados pelo Fórum Social Mundial. São eles: a solidariedade em equilíbrio com a autonomia individual, os bens sociais, o bem-estar de todos, a emancipação humana, o fortalecimento da pluralidade e da diversidade dos valores, a prioridade elevada atribuída aos direitos dos pobres e às suas iniciativas, a democracia enriquecida com mecanismos participativos e equilíbrio apropriado dos direitos civis e políticos com os direitos econômicos, sociais e culturais. Site do Fórum: $h t t p s: / / f s m 2016 . o r g / e n /(L A C E Y, 2010 ;$ FARIA, 2011). 
Para conduzir um programa de pesquisa é necessário primeiro identificar os tipos de possibilidades que queremos investigar - por exemplo, na agricultura, quais devemos preferir, as potencialidades, tais como as da biotecnologia, geradas pelas estruturas e leis subjacentes às coisas, ou as possibilidades das coisas como parte de agroecosres [sic] sociais, como por exemplo, a solidariedade e a justiça social - ou, do outro lado, a competitividade e a lucratividade. Mas quando adotamos uma estratégia e formulamos teorias, é necessário avaliar a teoria à luz dos dados e dos valores cognitivos. Em outras palavras, os valores sociais podem determinar as possibilidades de interesse, mas eles nunca podem mostrar exatamente, concretamente quais são as possibilidades. Para determinar quais são as possibilidades é necessário avaliar as teorias à luz de dados e valores cognitivos (LACEY, 2001).

De acordo com o modelo apresentado por Lacey, há dois níveis referentes às escolhas que precisam ser feitas em relação à pesquisa: o primeiro diz respeito aos tipos de estratégias que serão adotadas para guiar pesquisa e o segundo está relacionado a aceitação ou rejeição da teoria. A aceitação ou rejeição é caracterizada pela escolha entre teorias provisórias que, enquanto consideradas aptas, deverão se ajustar as restrições da estratégia que foi adotada. Lacey apresenta ainda um terceiro nível, relacionado ao momento de aplicação das teorias.

Aqui apresentamos os três níveis que se encontram nos dois volumes da principal obra de Lacey: Valores e atividade Científica 1 (2008) e 2 (2010). No artigo O modelo da interação entre as atividades científicas e os valores na interpretação das práticas contemporâneas, Hugh Lacey e Pablo Mariconda (2014) introduzem mais duas etapas à atividade científica, totalizando cinco etapas: 1) A adoção da estratégia de pesquisa, 2) O desenvolvimento da pesquisa, 3) a avaliação cognitiva das teorias e hipóteses, 4) a disseminação de resultados científicos e 5) a aplicação do conhecimento científico.

Os níveis apresentados também configuram os momentos importantes da atividade científica de acordo com o modelo proposto por Lacey. No primeiro momento, o que está em foco é a adoção da estratégia e a sua escolha envolve a sustentação de determinados valores e interesses. Durante o segundo momento não há intervenções de valores externos, o importante é a manifestação dos valores cognitivos em grau suficientemente alto, em relação a um conjunto apropriado de dados empíricos obtidos através da observação dos fenômenos, para conferir aceitabilidade à teoria. Em outras palavras, a teoria deve ser sustentada cognitivamente e o grau de cognitividade precisa ser alto de tal maneira que a teoria englobe as possibilidades apresentadas pelos fenômenos. A adoção de uma estratégia é, grosso modo, a identificação das possibilidades que se deseja alcançar (LACEY, 2010, p.69).

Nessa ocasião, a imparcialidade age como barreira, impedindo que valores não-cognitivos tenham algum papel para a escolha de teorias. O conhecimento produzido de acordo com a imparcialidade e desenvolvido segundo uma estratégia, poderá fornecer explicação para fenômenos e domínios com abrangência limitada, limites estes oferecidos muitas vezes pelos valores que motivaram a adoção da estratégia.

Desta forma, no momento de aplicação do conhecimento obtido, dificilmente a neutralidade almejada poderá ser sustentada, pois existe a possibilidade da pesquisa ser baseada em diversos interesses particulares e "as teorias tendem a servir preferencialmente os valores ligados a estratégias segundo as quais elas foram desenvolvidas e confirmadas" (LACEY, 2010, p. 114).

Além das estratégias de restrição e seleção existem outros tipos que possuem o mesmo objetivo: selecionar e restringir os dados a fim de testar teorias. O que as distingue é o modo como serão utilizadas e os objetivos almejados na utilização de cada uma. Lacey afirma:

Eu costumo falar de estratégias, por exemplo, estratégia materialista e estratégia de agroecologia, mas podemos falar também de estratégias feministas. A lógica é exatamente a mesma: as feministas têm valores e objetivos, produzir a igualdade de mulheres e homens, e questionam que tipo de conhecimento nós precisamos para concretizar esse projeto. Elas fazem críticas muito interessantes, especialmente em psicologia e psicobiologia, introduzindo novas abordagens nesse domínio, a partir de sua estratégia. Para mim é muito 
importante manter a distinção entre valor social e valor cognitivo, mas aceita essa distinção, pode existir uma abordagem feminista, uma abordagem agroecológica, uma abordagem racista se você quiser. Algumas feministas falam de ciência feminista; eu prefiro dizer que se trata de uma abordagem feminista da ciência, não de uma ciência completamente diferente. Mas geralmente, quando discutimos essas questões, as diferenças tendem a ser apenas terminológicas (LACEY, 2001).

Durante muito tempo a ciência tendeu a utilizar um tipo específico de estratégias consideradas como exemplares às práticas científicas: as estratégias materialistas de restrição e seleção ou de abordagem descontextualizadas (LACEY, 2010, p. 91).

Esse tipo de estratégia restringe a teoria de modo que esta represente os fenômenos de acordo com as leis da natureza, nos termos de sua geração, ordem, estrutura, processos e leis subjacentes. Os objetos dessa ordem subjacente são caracterizados em termos quantitativos e, assim, não podem ser interpretados tendo como base perspectivas valorativas, pois consideradas enquanto valores relativos à experiência humana, não são oriundas da ordem subjacente do mundo e, desta forma, são abstraídas do desenvolvimento da pesquisa científica.

A utilização da estratégia materialista se torna adequada, eficiente e legítima na medida em que o cientista se volta unicamente para os "fatos brutos" (LACEY, 2006, p.261) e para descobertas que levem a inovação tecnológica. Entretanto utilizar somente esse tipo de estratégia, dependendo do objeto de estudo, trará problemas referentes à implementação de tais inovações e para a investigação dos riscos.

É necessário reconhecer que as pesquisas baseadas em estratégias materialistas proporcionaram importantes inovações cientificas. O que deve ser colocado em questão não são as certezas científicas proporcionadas pelos resultados corretamente aceitos. O fundamental é esclarecer a que interesses esses resultados servirão e se a quantidade de pesquisa realizada será suficiente para analisar e descartar os riscos potenciais apresentados. E este fato se aplica, por exemplo, a pesquisa com alimentos geneticamente modificados.

Lacey afirma que existe uma relação de reforço mútuo entre a utilização de estratégias materialistas e a valorização moderna do controle, que constitui um valor social não sistematicamente subordinado a outros tipos de valores sociais. As inovações que manifestam esse tipo de valor são amplamente apreciadas, principalmente porque envolvem o controle sobre vários domínios da vida. O que Lacey denomina de valorização moderna do controle considera primeiramente a expansão do poder humano sobre os objetos naturais e a incorporação institucional desse controle, servindo principalmente aos interesses do capital e do mercado.

\section{Estratégias e Paradigmas: a pluralidade de estratégias para obtenção do bem-estar de todos}

Dois elementos importantes e complementares acerca do desenvolvimento da pesquisa científica foram apresentados: o paradigma que, utilizando os termos de Lacey, restringe os fatos que serão considerados por uma determinada comunidade para que esta possa conhecê-los mais profundamente e a estratégia que possui o papel de restringir o tipo de teoria considerada e selecionar os dados empíricos para o fim de testar as várias teorias provisoriamente mantidas.

Thomas Khun e Hugh Lacey convergem para uma concepção da ciência enquanto prática definida por um conjunto de normas, crenças e princípios compartilhados por determinado conjunto de indivíduos engajados em uma pesquisa. Enquanto Kuhn se dedica a análise da ciência básica atentado para o que ocorre no interior das práticas científicas, Lacey está preocupado com a aplicação do conhecimento obtido, ou seja, a ciência propriamente dita e suas aplicações.

Se, de acordo com Kuhn, o alvo da ciência é a resolução de quebra cabeças a sua verdadeira definição é demarcada por estratégias. Quando fenômenos e teorias aspirantes a paradigma são confrontados é necessário que, antes de o cientista se engajar na investigação, seja adotada uma estratégia de restrição e seleção que irá selecionar e restringir os tipos de dados e teorias aceitáveis (LACEY, 2010, p. 69). 
No modelo de atividade científica proposto por Kuhn, a ciência opera com a utilização de um paradigma. Este é adotado para beneficiar a caracterização e solução dos quebra-cabeças que se apresentam à pesquisa. Enquanto permanecer fecundo o paradigma (ou a estratégia) obterá exclusividade dentro da pesquisa que será conduzida com base nele. (LACEY, 2010, p. 69).

Tendo em vista as diversas metodologias existentes, voltamos as seguintes questões: levando em consideração que a utilização de um único paradigma (ou estratégia) poderá gerar um conhecimento limitado acerca de determinado objeto de investigação, que meios poderão ser utilizados na pesquisa científica para que os seus resultados possam abarcar todas as possibilidades envolvidas? Em outras palavras (utilizando os transgênicos como exemplo), que tipo de estratégias devem ser selecionadas para que os resultados das pesquisas sobre os alimentos transgênicos alcancem da melhor maneira possível tanto as aspirações do progresso tecnológico quanto os anseios sociais e ecológicos?

Lacey afirma ser possível a utilização de uma pluralidade de estratégias na ciência, desde que sejam escolhidas estratégias que se complementem. Considerando este ponto de vista, a proposta de Kuhn, que se baseia em um único paradigma vigente, não consegue abarcar todas as possibilidades em jogo na pesquisa científica.

Uma vez que a pesquisa, segundo a perspectiva kuhniana, se torna cada vez mais orientada e especializada com a emergência de novos paradigmas fruto das revoluções científicas, o conhecimento produzido poderá tornar-se cada vez mais cimentado ou menos sujeito à flexibilidade.

Aqui, não há intenção de colocar um caráter negativo para a especialização, ao contrário, ela gera muitos benefícios para pesquisa, mas é necessário reconhecer que a especialização pode tornar a pesquisa deficiente limitando e fragmentando o conhecimento produzido. O conhecimento se torna cada vez mais amplo a respeito de um determinado campo cada vez mais restrito.

Este fato configura um problema do processo de especialização e se torna claro na exposição de Lacey acerca das estratégias materialistas ou de abordagem descontextualizada. Não podemos negar que as pesquisas baseadas em tais estratégias geraram enorme quantidade de descobertas cientificas e inovações tecnológicas, mas também é necessário ponderar que as estratégias materialistas possuem um caráter limitador para a pesquisa, pois analisam os fenômenos nos termos de sua geração, sua estrutura, processos e leis subjacentes, dissociando-os de seus contextos sociológicos, históricos, da experiência humana e vinculação com valores externos a ciência (LACEY, 2006, p. 17).

Sem a intenção de fornecer limites para o esquema kuhniano, utilizamos mais uma vez o exemplo apresentado por Lacey, sobre as pesquisas com sementes transgênicas. A pesquisa sobre transgênicos é baseada em um único tipo de metodologia ou, de acordo com Lacey, em estratégias materialistas ou abordagem descontextualizada:

A mercantilização das sementes, no entanto, não representa um valor universal e, assim, ceterisparibus, as práticas de pesquisa que aumentam nossa compreensão das possibilidades dos transgênicos não serão universalmente consideradas de elevado valor social. Considere-se dois tipos de possibilidades sobre a produção de colheita. O primeiro diz respeito a sua serventia ao bem-estar humano local e a sustentabilidade do meio ambiente; o segundo refere-se à maximização sob condições amplamente replicáveis. Aqueles que adotam exclusivamente as estratégias $\mathrm{AD}^{5}$ (incluindo aquelas da biotecnologia) são efetivamente capazes de abordar questões sobre o segundo tipo, mas questões sobre o primeiro tipo não podem ser abordadas, se alguém as dissocia dos contextos sociais e ecológicos. As questões do primeiro tipo, contudo, terão maior importância para aqueles cujos valores estão em conflito com os valores do progresso tecnológico e os valores socioeconômicos (por exemplo, o crescimento econômico) que são usualmente incorporados nas poderosas instituições modernas. Assim, uma vez que essas questões estão abertas à investigação

5 Estratégias de Abordagem Descontextualizadas. Possuem a função de dissociar a pesquisa de toda a carga valorativa que possa impedir a obtenção de um conhecimento baseado em valores cognitivos e obtido de acordo com o ideal de imparcialidade. 
empírica sob estratégias agroecológicas, estas estratégias corretamente ganharão precedência (LACEY, 2012, p.441).

Para abarcar as possibilidades relacionadas ao desenvolvimento das pesquisas com culturas transgênicas, a utilização das estratégias materialistas se mostra suficiente, mas se a intenção for também explorar e entender as possibilidades apresentadas pela agroecologia e o impacto da cultura transgênica sobre vida humana e o meio ambiente, a utilização de outros tipos de estratégias complementares configura uma solução importante (LACEY, 2010, p. 131).

A pluralidade apresentada deve ser fecunda, constituída por estratégias que se complementem a fim de atingir certa "democracia" no interior da pesquisa e na aplicação de seus resultados. Lacey afirma:

Em geral, as possibilidades encapsuladas pelas teorias desenvolvidas sob diferentes estratégias sobrepõem-se, no máximo, por sugerirem que um "entendimento completo" dos fenômenos do mundo da experiência vivida não pode ser obtido (mesmo a princípio) se for submetido a apenas um dos tipos de estratégias. Essa é a base para a complementariedade das estratégias (LACEY, 2012).

Existe a necessidade de empreender investigações acerca de áreas pouco pesquisadas e cautela diante da aplicação tecnológica. Tais aspectos, muitas vezes, não são favorecidos diante da utilização somente de estratégias materialistas, havendo a necessidade do uso de outros tipos de estratégias.

Em relação aos riscos da implementação de inovações tecnológicos, Lacey apresenta o princípio de precaução. A utilização desse princípio poderá trazer diretrizes importantes para a aplicação do conhecimento técnico científico. Segundo o princípio de precaução ao surgirem atividades que possam gerar danos à sociedade e que sejam consideradas cientificamente plausíveis, mesmo que a incerteza sobre tais danos impere, é necessário que sejam aplicadas medidas com o fim de diminuir os danos possíveis (definição sugerida pela Comissão Mundial sobre Ética da Ciência e da Tecnologia da Unesco - COMEST).

Assim, o pluralismo estratégico (conduzido por estratégias fecundas) não descarta a utilização das chamadas estratégias materialistas. Ele permite a utilização dessas com outros tipos de estratégias, possibilitando uma abrangência maior do conhecimento produzido. Este fato também torna plausível a recuperação do ideal de neutralidade que terá mais chances de se tornar eficaz nas práticas científicas.

Para garantir a abrangência de entendimento sobre os fenômenos é importante que a pesquisa seja conduzida por uma multiplicidade de abordagens, uma vez que há diversas questões, interesses e valores envolvidos desde o momento do estabelecimento das metodologias, que serão a base dos estudos sobre determinado objeto, até a aplicação dos resultados obtidos pela pesquisa.

\section{Considerações finais}

Neste estudo foi sustentado que a investigação baseada em uma única estratégia pode comprometer e muito a análise e a abrangência do conhecimento obtido através das pesquisas científicas. A determinação de padrões e critérios únicos para todos os campos de pesquisa se tornou quase impossível de ser concretizada.

O processo de produção do conhecimento precisa envolver a utilização de critérios cognitivos válidos para que a teoria seja corretamente aceita, mas é necessário também considerar as possibilidades que podem ser alcançadas com ela, principalmente no que diz respeito a resposta aos valores e anseios envolvidos, sejam eles sociais, ecológicos, corporativos ou institucionais, por exemplo.

A utilização de uma única metodologia ou estratégia (como o caso da utilização de estratégias materialistas) pode tornar a pesquisa deficiente, mesmo considerando que esses tipos de estratégias forneceram durante muito tempo inovações e tecnologias significativas. 
A seleção das metodologias ou estratégias complementares pode variar de acordo com as características do objeto de investigação e com o objetivo que se deseja atingir. Deste modo, o objetivo da ciência de obter um conhecimento confiável e cada vez mais fundamentado poderá ser alcançado.

De um lado temos uma valorização do controle da natureza e das tecnologias produtivas pelas grandes indústrias e órgãos internacionais através do progresso tecnológico; do outro lado existem em pauta valores sociais não subordinados à valorização moderna de controle, mas ligados principalmente ao bem-estar humano e a sustentabilidade.

Com a utilização de um único método de pesquisa alguma das posições sofrerá perdas e a ciência moderna deixa evidente que o controle da natureza e de seus processos, os valores sociais, ecológicos e aqueles que estão relacionados ao bem-estar humano estão, acima de tudo, consideravelmente subordinados ao "valor da implementação de novos desenvolvimentos tecnocientíficos" (LACEY, 2008, p. 81).

Um dos questionamentos mais recentes acerca da ciência se refere aos benefícios que esta pode oferecer à vida humana e como seus resultados podem ser articulados de modo a minimizar os danos ao meio ambiente. A ciência moderna durante muito tempo afirmou que questionamentos desse tipo não poderiam ser colocados em pauta, uma vez que a ciência deveria ser destituída de qualquer perspectiva de valor. Ademais sustentava também que a ciência produziu inovações para o bem e que ofereceram (e ainda oferecem) novas possibilidades para a vida humana.

A utilização de várias estratégias ou abordagens não implica em fracasso no alcance dos objetivos da ciência. Valores éticos, sociais e culturais, por exemplo, podem ter influência positiva na investigação cientifica e, também, podem oferecer impactos positivos às estratégias adotadas. Mas, ao se referir a valores desses tipos, não podemos concluir que todo e qualquer valor possa contribuir de forma positiva. É necessário observar quais tipos de valores estão em jogo e quais serão importantes para atingir o objetivo proposto.

A promoção do bem-estar de todos, e que este prevaleça como um dos objetivos da ciência, está inteiramente ligada a condução das práticas científicas, a sua estrutura e a própria situação atual da ciência, caracterizada pela relevância do seu caráter social e histórico.

O que observamos nos dias atuais é que a ciência e a sua prática estão cada vez mais apressadas, sujeitas a prazos e a investimentos corporativos, institucionais e governamentais que visam, principalmente o lucro e o bem-estar de um pequeno grupo. O conhecimento científico obtido pode ser utilizado tanto para fins pacíficos quanto para fins hostis. Este fato não constituiria a própria ciência como ré, mas sim os indivíduos responsáveis pelo desenvolvimento e aplicação do conhecimento obtido através da pesquisa (LACEY, 2010, p. 95). 


\section{Referências Bibliográficas}

FARIA, Glauco. O pai do FSM: Oded Grajew relembra como foram os primeiros passos para a criação do Fórum Social Mundial. Revista Fórum, 22 de outubro de 2011. Disponível em: http://www.revistaforum.com.br/2011/10/22/o-paido-fsm/ Acesso em: 07/09/2016.

HACKING, Ian. Representar e Intervir: tópicos introdutórios de filosofia da ciência natural. Rio de Janeiro: EdUERJ, 2012.

KUHN, Thomas. A Tensão Essencial. Lisboa: Edições 70, 1977.

A estrutura das revoluções científicas. São Paulo: Perspectiva, 1992.

. O caminho desde A Estrutura: ensaios filosóficos, 1970-1993, com uma entrevista autobiográfica. São Paulo: UNESP, 2006.

LACEY, Hugh. Entrevista com Hugh Lacey. Revista Teoria e Debate, $\mathrm{n}^{\circ}$ 46, nov./dez./jan. de 2001. Entrevista concedida à José Corrêa Leite e Marcos Barbosa de Oliveira. Disponível em: <http://csbh.fpabramo.org.br/o-que-fazemos/editora/teoria-e-debate/edicoes-anteriores/ entrevista-hugh-lacey> Acesso em: 23/08/2016.

. Is Science value free? Values and scientific understanding. Londres: Routledge, 2005.

. A controvérsia sobre os transgênicos: questões científicas e éticas. São Paulo: Ideias \& Letras, 2006.

O princípio de precaução e a autonomia da ciência. Scientiae Studia. São Paulo, v. 4, n. 3, p. 373-392, 2006.

. As relações entre fato e valor. Cadernos de Ciências Humanas - Especiaria, v. 9, n. 16, p. 251-266, jul./dez, 2006.

. Valores e atividade científica 1. São Paulo: Associação Filosófica Scientiae Studia/Editora 34, 2008.

. Entrevista: Hugh Lacey. Trab. Educ. Saúde, Rio de Janeiro, v. 7, n. 3, p. 623-628, nov. 2009 a fev. 2009.

. Valores e atividade científica 2. São Paulo: Associação Filosófica Scientiae Studia/Editora 34, 2010.

. Pluralismo metodológico, incomensurabilidade e o status científico do conhecimento tradicional. Scientiae Studia. São Paulo, v. 10, n. 3, p. 425-453, 2012.

LACEY, Hugh; MARICONDA, Pablo. O modelo da interação entre as atividades científicas e os valores na interpretação das práticas contemporâneas. Estudos Avançados, São Paulo, v. 28, n. 82, 181-199, 201

LANTIMAN, Camila Claudino. A interação entre ciência e valores segundo Hugh Lacey: estratégias, controvérsias e a garantia do bem-estar de todos. 2015. 92 f. Dissertação (Mestrado em Filosofia) - Instituto de Filosofia e Ciências Humanas, Universidade do Estado do Rio de Janeiro, Rio de Janeiro, 2015.

MENDONCA, André Luis de Oliveira; VIDEIRA, Antonio Augusto Passos. Progresso científico e incomensurabilidade em Thomas Kuhn. Scientiae Studia, v. 5, n.2, p. 169-183, 2007. 